\title{
A Comparative Analysis of the Two Main Documents Used in Small and Medium-Sized Enterprises in France and Québec as a Framework for Improving Occupational Health and Safety
}

\author{
Chloé Bignon1, Adel Badri2,3* \\ ${ }^{1}$ Department of Health Sector Engineering and Associated Bioproducts, Istia Graduate School \\ of Engineering, University of Angers, Angers, France \\ ${ }^{2}$ Industrial Engineering Department, School of Engineering, Université du Québec à Trois-Rivières, \\ Trois-Rivières, Canada \\ ${ }^{3}$ Research Institute on SMEs, Université du Québec à Trois-Rivières, Trois-Rivières, Canada \\ Email: ^Adel.Badri@uqtr.ca
}

How to cite this paper: Bignon, C. and Badri, A. (2019) A Comparative Analysis of the Two Main Documents Used in Small and Medium-Sized Enterprises in France and Québec as a Framework for Improving Occupational Health and Safety. Open Journal of Safety Science and Technology, 9, 22-36.

https://doi.org/10.4236/ojsst.2019.91003

Received: January 8, 2019

Accepted: March 4, 2019

Published: March 7, 2019

Copyright $\odot 2019$ by author(s) and Scientific Research Publishing Inc. This work is licensed under the Creative Commons Attribution-NonCommercial International License (CC BY-NC 4.0). http://creativecommons.org/licenses/by-nc/4.0/

\begin{abstract}
Context and background: In France as in Québec, occupational health and safety (OHS) has become a national priority. While organizations in these two societies differ slightly, preventive measures are the same, and legislation requires that the chosen approach to improving OHS be reduced to writing, even in small and medium-sized enterprises. Prevention is managed through existing structures within companies and is documented by the employer. Such documentation is mandatory and allows the company to manage its risks and to monitor the hazards associated its activities. The principal document used for this purpose is known as the "Document unique" in France and the "Programme de prevention" in Québec. Motivation: The aim of this concise review of the literature is to compare the "Document unique" and the "Programme de prevention" and thereby help experts develop a universal document that combines the best features of the French and Québécois versions. Methods: Differences between these two documents are noted. Through comparative analysis, we explain how prevention, the regulatory context and the field of application are defined in each case. We then discuss the helpful features and the limitations inherent in both documents and conclude with a table of comparison. Results and conclusions: The advantages and inconveniences appear to be similar for both documents. There are nevertheless opportunities to combine the best features of the Document unique
\end{abstract}


and the Programme de prévention in order to obtain an improved guide for the writing of a complete accident prevention and OHS policy appreciated by employers and employees alike.

\section{Keywords}

Occupational Health and Safety, Prevention, Document Unique, France, Programme de Prévention, Québec

\section{Introduction}

Worker safety is essential for the success of any business. Small and medium-sized enterprises in particular face a variety of difficulties in their quest to reduce or eliminate occupational risks, due in large part to their scale of operation and limited resources. In Europe, nearly $80 \%$ of workplace accidents leading to more than three days of absence and nearly $88 \%$ of fatal accidents occur in this business category [1]. In terms of economic and social costs, improving accident prevention represents major savings [2].

Worker wellbeing and physical health are essential for business longevity [3]. Occupational health and safety (OHS) is the discipline of preventing workplace accidents and occupational illnesses through actions implemented in the work environment. Risk management is one of the principal activities undertaken in order to combat all types of occupational injury or illness [4].

According to article L.4121-1 of the French labor code, the workplace safety imperative obliges all employers to implement measures designed to ensure the safety and protect the health of their employees [5]. A key element of the approach to meeting this obligation is risk evaluation. In France, this approach is reduced to writing in a framework entitled "Document unique" [6], the purpose of which is to lessen or eliminate OHS risks by identifying them and implementing corrective actions.

Employers in Québec are required to do likewise using a framework entitled "Programme de prévention" [7]. Like the Document unique, the aim of this program is to list, monitor and eliminate potential hazards while proposing concrete actions in order to ensure worker safety and health. The Programme de prévention is intended as the principal tool to be used in order to achieve compliance with Québec occupational health and safety legislation [8]. Based on risk identification and corrective measures, its goal is thus prevention, indeed elimination of work-related hazards.

In this article, some notable differences between these two documents are brought to light. Through comparative analysis, we explain how prevention, the regulatory context and the field of application are defined in each case. We then discuss the helpful features and the limitations inherent in both documents and conclude with a table of comparison.

The research problem is presented in Section 2, followed by the research me- 
thodology in Section 3 and the detailed comparative analysis in Section 4. Our intention is to help experts enrich these documents for application to prevent work-related accidents and illnesses in small and medium-sized enterprises.

\section{Research Problem}

With regard to small and medium-sized enterprises, we note three recurrent problems in the production and content of the in-house OHS documents currently in use. To begin with, depending on the business size and priority category, the Programme de prévention may or may not be mandatory. A program should be required for nearly all businesses, since risks are present in several sectors of activity not listed as high-priority in the legislation [8]. Each business may create its own document, resulting in contents differing vastly in both form and substance. The current legislation proposes no model, and each employer writes as he or she sees fit [5] [9]. Risks and the associated preventive actions are often described in generalities rather than in concrete terms that correspond to workplace activities. Such documents can contribute little to effective management of accident prevention. And finally, although the creation of the document should involve the workers, these employees are rarely well informed or trained in the subject matter, and often consider the resulting content to be difficult to implement.

The Programme de prévention generates documents that are a very complex and often too theoretical, as well as lacking uniformity of presentation and richness of content. Our goal is to make the framework simpler, readily adaptable to small and medium-sized industrial enterprises and designed to yield documents that are more easily understood and provide concrete examples of feasible actions.

By comparing the contents of the principal OHS documents in France and Québec, it should be possible to propose an enriched prevention document framework for small industrial enterprises in Québec. Our intention is not to propose specific solutions, but to compare French and Québec experiences with prevention in the workplace, in order to move closer to the creation of a single type of document that enables small and medium-sized enterprises to implement effective actions more easily and thus eliminate hazards and improve their productivity.

\section{Research Methodology}

This research was conducted in two phases (Figure 1). The subject of the present article is the findings of our review of the literature (the first phase). The proposal of a universal document for the prevention of workplace accidents and work-related illnesses (the second phase) will be covered in a future article.

\subsection{Literature Review}

Publications containing references to Document unique and Programme de prevention were identified by searching the Internet using Google and searching 


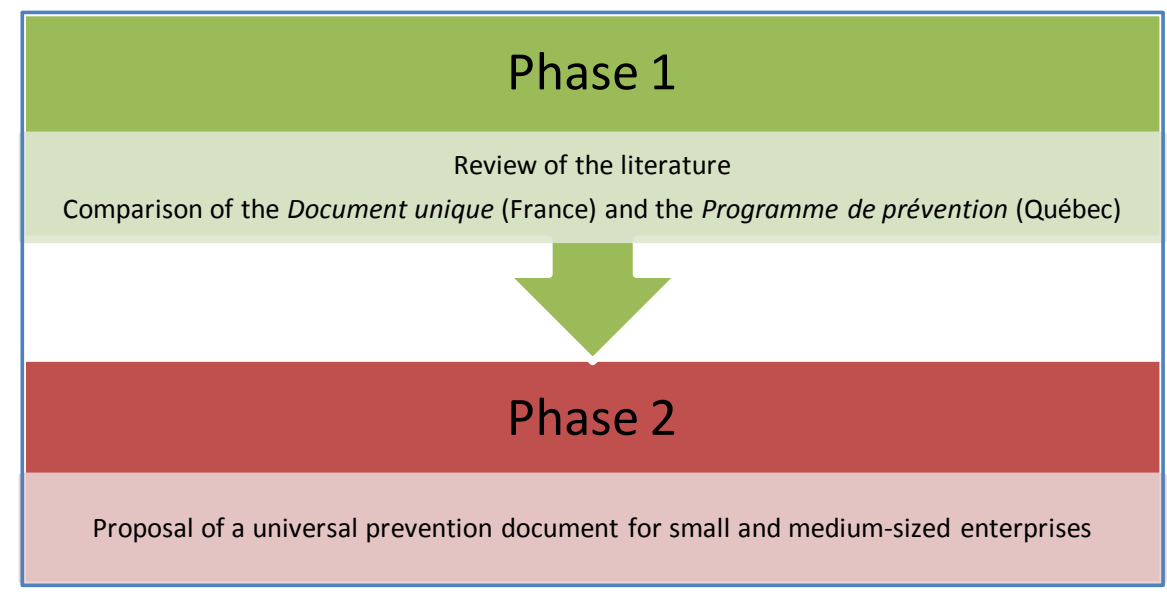

Figure 1. The phases of the research methodology.

in the following databases: Commission des normes, de l'équité, de la santé et de la sécurité du travail (CNESST, Québec), Institut de recherche Robert-Sauvé en santé et en sécurité du travail (IRSST, Québec) and Institut national de recherche et de sécurité (INRS, France). Among the documents thus retrieved, the following types were examined: articles in magazines and scientific journals, technical reports, standards, regulations and laws.

It should be noted that the search was conducted in French only, since only francophone organisations use the two OHS frameworks being compared. Furthermore, the documents were retrieved only from the literature published in French and therefore include relatively few scientific articles. The various searches nevertheless retrieved a sufficient number of articles to allow a comparative analysis. Relevant publications were assessed for the clarity of their objectives and results. We analyzed the titles, keywords and abstracts of more than 60 publications. We were able to extract definitions and fields of application as well as advantages and limitations associated with each of the two national OHS models. The helpful features and inconveniences of these frameworks are summarized in a table presented below.

\subsection{Development of a Universal Prevention Program}

A future goal of this research is to propose a model of the Programme de prévention enriched with elements drawn from the Document unique in order to obtain a framework better adapted to the needs of small and medium-sized enterprises in Québec.

This new framework will be developed in steps, the first of which will be compilation of the information gathered from the comparative analysis. In the second step, the advantageous features of the Document unique and the Programme de prevention approaches will be combined in order to produce an enriched, adaptable and user-friendly universal prevention program for small and medium-sized industrial enterprises. Risks will be grouped into industrial categories to allow businesses to determine quickly whether or not a risk or cat- 
egory of risks and the associated recommendations are applicable to their situation.

\section{Results}

\subsection{Occupational Health and Safety in Small and Medium-Sized Enterprises}

The small and medium-sized enterprises category may be characterized as "human-sized". It generates a major portion of the national wealth and provides much of the employment [2] [10] [11]. The size of a business is defined primarily in terms of the number of employees and its annual sales. The exact definition may change from one country to the next [12]. In France, the small to medium-sized category refers to private companies employing no more than 250 individuals. Companies employing 10 to 50 individuals and generating annual sales not exceeding 10 million euros or employing 50 to 250 individuals and generating annual sales not exceeding 50 million euros are in this category [12]. The European commission recommends defining the category also in terms of social and financial characteristics [13]. In Canada, a small to medium-sized business employs no more than 500 individuals and has assets not exceeding 50 million dollars, of which no more than $25 \%$ are the property of a large company [14].

The small to medium-sized category thus includes a wide diversity of business models each requiring specific managerial methods. Depending on the sector of activity, such companies may face numerous risks in the workplace setting. If these are not reduced, occupational injuries, illnesses and infirmities will reduce worker efficiency and hence the productivity of the enterprise. Proper management of prevention is therefore fundamental for the success of a small or medium-sized business [15].

Fatal accidents are up to eight times more frequent in small enterprises than in large ones [16]. In Europe, $82 \%$ of workplace accidents and 90\% of those causing death occur in small enterprises. The tools of accident prevention must be adapted to the size of the business and to its industrial setting. Business size of course has a major influence on the availability of financial resources for such tools [17], cost being one of the main obstacles to improving prevention. Small companies cannot afford to manage OHS using the means available to large corporations [2]. Paperwork, time constraints and lack of staff are among the factors that contribute to their poorer management of OHS. According to a study based on over 200 interviews, 9 out of 10 directors of such companies have insufficient knowledge in accident prevention and its integration into operations [17]. While large companies often have specialized staff dedicated to OHS risk management and accident prevention, such personnel are usually non-existent in small companies. OHS-related information is communicated rarely, the director or CEO often being the only person who does this [2] [17].

Obstacles associated with managers must also be taken into consideration. 
Most managers lack the skills needed to manage OHS in collaboration with company directors [17]. Quite often workers and employers alike are too preoccupied with production to spend time on accident prevention. Lack of training and lack of time appear to be obstacles for about $30 \%$ of the directors interviewed [17].

In a more recent study of the factors associated with inefficient management of OHS in smaller businesses, human conditions and economic uncertainty were found to play a significant role, followed by lack of sensitization of directors [2]. Managers and directors often simply lack the OHS reflex, creating barriers to the integration of $\mathrm{OHS}$ principles into workplace design and operations. In some businesses, OHS management continues to be regarded as optional and not essential for smooth operation and sustainable productivity. Finally, since the managers of such companies are not well informed on the subject, they often view the creation of a prevention document as an overly technical, constraining, expensive and ultimately unproductive effort.

Integration of $\mathrm{OHS}$ generally involves the development of a rigorous approach to prevention. A prevention program is indispensible if work-related infirmity is to be reduced and increases in productivity are to be sustainable in smaller enterprises. However, managers of these enterprises do not always appreciate the connection between OHS and operational efficiency [2] [11].

\subsection{Prevention Documents in France and in Québec}

\subsubsection{The Document Unique in France}

An effective approach to prevention is one that ensures the health and safety of employees in their workplace. The employer must therefore root out hazards associated with the work and reduce or eliminate these by implementing concrete actions.

In the French system, the State and its ministerial staff have direct control over OHS, unlike in Québec, where the role of managing prevention in the small to medium-sized business category is delegated to independent agencies. Two ministries thus work in close collaboration: the ministry of labor and the ministry of health. The general directorate of labor is responsible for preventive aspects while the directorate of social security ensures worker compensation and participates in guiding prevention policy. The State does consult some external organizations [18].

The Document unique has been the principal reference in matters of prevention in France since November 2001. In accordance with article R230-1 of French OHS legislation, employers are required to use this document to transcribe the results of their OHS risk evaluations [19]. This allows them to list and rank all risks that could pose threats to worker health and safety in the work environment. The production of this document is mandatory for businesses and associations having more than one salaried employee. It must combine, on a single support, the identification of occupational risks, a record of the approach taken to evaluate these risks, and planning of short-term, medium-term and 
long-term preventive actions. It takes into account the inherent characteristics of the business operations such as the number of salaried workers exposed to each risk (exposure) or the frequency with which the risk arises. These indicators are indispensible for improving accident prevention within a company [6].

The Document unique represents the application of articles L4121-2 and L4121-3 of the French labor code, as per decree number 2001-1016 issued on November 5, 2001 [5] and requiring all employers to reduce their risk evaluation to writing for compliance with the labor code [6]. However, the legislation sets forth only the minimal requirements and does not propose a model document. The employer can therefore choose the format best adapted to his enterprise. Although no rule has been issued for dating or signing, dating of updates is recommended in order to ensure the traceability of amendments [6].

The Document unique is not to be produced solely for compliance with regulations. It is designed to evolve and to be used as a tool in support of implementation of preventive measures or actions for the purpose of improving OHS. Article L4121-2 of the labor code specifies that the employer must base the implementation of such measures or actions on "the general principles of prevention", summarized in Table 1.

According to decree 2001-1016, updating of the Document unique is mandatory and indispensible in order to allow it to evolve along with the business [21]. The document must be updated at least once a year as well as after each workplace accident report. It should also be reviewed each time a work task or activity is modified. It must be allowed to adapt to changes to the company and its enterprises. French inspectors are saddled with the task of verifying that enterprises are compliant with their legal and regulatory frameworks as well as the terms of labor agreements.

In order to create a Document unique, an employer may use previous in-house documents. Written reports describing the sanitary, safety and working conditions overall may be used as references [22]. The employer may also enlist any person wishing to get involved in the company OHS and prevention initiative. In addition to contributions from employees, help from the sanitary, safety and working conditions committee (CHSCT), workplace health services committee or consulting and training organizations also may be sought [23]. Numerous consulting firms offer the service of writing the Document unique according to the specific needs of small businesses. Workplace medical doctors can also help with the writing. In any case, the employer remains responsible for the document.

The Document unique is to be used also as a base for writing the annual prevention program, a more general document that combines technical, organizational and human aspects with reference to the nine general principles of prevention listed in Table 1.

\subsubsection{The Programme de Prévention in Québec}

The Québec equivalent to the French Document unique is the Programme de prévention, which contains the details of all actions (organizational and operational) 
Table 1. The nine general principles of prevention [20].

\begin{tabular}{|c|c|c|}
\hline No. & Principle & Meaning \\
\hline 1 & Avoiding risk & Eliminating the hazard or exposure to it \\
\hline 2 & $\begin{array}{l}\text { Evaluating unavoidable } \\
\text { risks }\end{array}$ & $\begin{array}{l}\text { Appreciating their nature and importance in order to } \\
\text { determine actions that ensure worker health and safety }\end{array}$ \\
\hline 3 & Tackling risks at the source & $\begin{array}{l}\text { Integrating prevention as early as possible, in the design of the } \\
\text { workplace, equipment and tasks }\end{array}$ \\
\hline 4 & Adapting work to people & $\begin{array}{l}\text { Designing workstations and choosing equipment and methods } \\
\text { that minimize the monotony, drudgery and cadence of tasks }\end{array}$ \\
\hline 5 & $\begin{array}{l}\text { Allowing techniques } \\
\text { to evolve }\end{array}$ & $\begin{array}{l}\text { Watching for opportunities to install preventive means in } \\
\text { phase with technical and organizational evolution }\end{array}$ \\
\hline 6 & $\begin{array}{l}\text { Replacing hazardous means } \\
\text { with safer ones }\end{array}$ & $\begin{array}{l}\text { Eliminating dangerous products or processes when the same } \\
\text { result is obtainable using less hazardous means }\end{array}$ \\
\hline 7 & Planning prevention & $\begin{array}{l}\text { Integrating work technique, structure and conditions, social } \\
\text { relations and the environment into a coherent unit }\end{array}$ \\
\hline 8 & $\begin{array}{l}\text { Implementing measures of } \\
\text { collective protection }\end{array}$ & $\begin{array}{l}\text { Giving priority to collective protection means, using personal } \\
\text { protective devices only to enhance collective protection (not to } \\
\text { compensate for inadequate collective means) }\end{array}$ \\
\hline 9 & $\begin{array}{l}\text { Giving appropriate } \\
\text { instructions to workers }\end{array}$ & $\begin{array}{l}\text { Giving employees the information necessary to perform their } \\
\text { tasks under conditions of optimal safety }\end{array}$ \\
\hline
\end{tabular}

planned and implemented in the continued effort to improve OHS in a business establishment [7].

The Programme de prévention is the principal tool of reference for the purposes of OHS legislation (LSST) in Québec [8] [9]. Its aim is to prevent, indeed to eliminate hazards in the workplace. This program proposes a list of potential hazards and concrete actions for limiting them. These risks and hazards are based on work-related injuries and infirmities compiled by the CNESST [24].

Within the rather elaborate Québec regulatory framework, employers are obliged to identify, monitor and eliminate hazards that could affect their workers [8]. They must also verify that their workers are aware of and apply the preventive measures that ensure a safe and healthy work environment. Writing the Programme de prévention is an obligation for any establishment subject to this regulation, including small businesses. The criteria that determine who is subject to the regulation include the number of salaried employees and the presence of high-priority activities (high-risk jobs).

Devised in 2001, the occupational health and safety regulation (RSST) defines the workplace and task-related requirements and obligations with which employers must comply [25]. It establishes standards and provides clear guidelines for organizing accident prevention programs. All organizations subject to OHS legislation use this regulation as their principal reference. It is divided into several sections, including arrangement of work areas, emergency safety measures, work environment quality, combustible dust and dry matter, radiation, noise, lighting, procedures regarding dangerous substances, machinery and equipment, personal safety devices, collective protective means and so on. 
The Programme de prevention must be updated annually [9], must reflect changes and evolution within the business establishment and must include an evaluation of compliance with in-house standards from the previous year. The updating process thus provides proof that the document is dynamic and evolving. The writing of this document is mandatory for all business establishments subject to the Programme de prévention [8] [9]. Establishments active only in non-listed categories are certainly not discouraged from being proactive in this regard.

The CNESST thus highly recommends implementing a prevention program. As is the case for the Document unique, the employer is responsible for the Programme de prévention and may seek the assistance of consultants and agencies. Guides designed specifically for small enterprises propose a simple and practical approach to reducing the most common OHS hazards [26].

The principal steps to be followed in order to create a document suitable for the purposes of the Programme de prévention are shown in Figure 2.

\subsection{Advantages and Drawbacks of Prevention Documents}

\subsubsection{The Document Unique in France}

The Document unique is a tool that employers use to record and evaluate initiatives undertaken to reduce risks faced by their employees. It thus constitutes at the same time an inventory of risks present in the workplace and a plan of action designed to reduce or eliminate them. Using the Document unique to monitor risks makes a company's commitment to OHS more credible [6]. A statistical follow-up may be implemented in order to monitor the success of prevention initiatives.

By decreasing work-related hazards, the employer improves operations, utilizes know-how and reinforces social protection. Expenses due to workplace accidents and absenteeism decrease and productivity increases. Annual updating provides indicators of effectiveness and thereby contributes to the dynamism of the document and of the business [21].

However, it is the employer who must write the Document unique, which is often perceived as making an already heavy workload insurmountable. This task therefore must not be left to the company director but rather should be a participative effort involving workers and specialized organizations. The legislation currently does not propose any model for the document, and the employer may use the support (paper, spreadsheet or dedicated software) best suited to company needs and resources [23].

The advantages and drawbacks of two types of software support are listed in Table 2.

\subsubsection{The Programme de Prévention in Québec}

The Programme de prévention proposes actions in order to prevent or eliminate hazards present in the workplace. This OHS document is very complete and contains a large amount of data, combining a list of the principal hazards 


\section{Initiate and coordinate the effort}

\section{Develop a document production schedule}

3.Define the problems and risk factors present in the establishment

4. Designate the persons responsible for devising the corrective measures

5. Develop a plan of action for prevention

6. Devise a formula for annual evaluation of the actions

Update the plan of action annually

Figure 2. The 7 steps of the creation of an OHS plan based on the Programme de prévention [27].

Table 2. Advantages and drawbacks of using spreadsheets or dedicated software for producing the Document unique [28].

\begin{tabular}{|c|c|c|}
\hline Support & Advantages & Drawbacks \\
\hline $\begin{array}{l}\text { Dedicated } \\
\text { software }\end{array}$ & $\begin{array}{l}\text { - Considerable masses of data are } \\
\text { processed, sorted and ranked. } \\
\text { - The criticality calculation system is } \\
\text { usually automatic. } \\
\text { - The evolution of the document is saved } \\
\text { and archived. } \\
\text { - Generates other prevention tools: plan } \\
\text { of action, analysis of accidents, etc. } \\
\text { - Access is controllable; two or more } \\
\text { users may work simultaneously. }\end{array}$ & $\begin{array}{l}\text { - Training of users is lengthy and } \\
\text { constraining. } \\
\text { - Expensive. } \\
\text { - The client needs to be accompanied } \\
\text { (file set-up and client service). } \\
\text { - Sensitive to computer system bugs. }\end{array}$ \\
\hline Spreadsheet & $\begin{array}{l}\text { - Use is simple and flexible. } \\
\text { - Inexpensive. } \\
\text { - Databases are accessible and easily } \\
\text { integrated into other systems. }\end{array}$ & $\begin{array}{l}\text { - Time required for modeling, set-up } \\
\text { and construction of indicators and } \\
\text { methods of calculation. } \\
\text { - Manual updating of data requires } \\
\text { rigor and concentration (tedious). } \\
\text { - Sensitive to computer system bugs. }\end{array}$ \\
\hline
\end{tabular}

encountered as well as regulations and standards to be met in responding to them. It also lists personal safety devices and protective equipment. Employers and workers participate in the production of this document [26]. Writing the Programme de prévention thus favors the commitment of company directors and staff. This improves wellbeing in the workplace, allowing workers to feel safer and valued by their employer [29].

The Programme de prévention is used as a base for building an overall OHS management system, thus allowing the employer to gather all information that the company might need for the purposes of prevention. It constitutes evidence of company organization, rigor and commitment regarding the challenge of improving OHS. 
An annual update must be filed with the CNESST as a sign that company is active and dynamic in its approach. The document thus reflects the evolution of the business and its prevention initiative [26] [27]. These benefits lead to satisfaction with the Programme de prévention among employers and workers alike. By ensuring worker wellbeing, the company improves its work climate and thereby decreases absenteeism and improves its productivity [29].

Since it is known that OHS is fundamental for the proper functioning and productivity of a business, a prevention program should be an obligation for all enterprises. However, the legislation requires it only for a few categories considered as high priority [9]. The Programme de prevention currently protects only about 26\% of the Québec labor force [30]. Many small and medium-sized enterprises are not subject to the requirements of the Programme de prévention. The risks present in several sectors not listed as high priority by the LSST are therefore receiving less attention [9] [26].

Although workers are involved in the management of accident prevention in their workplace, few are sufficiently informed with regard to the Programme de prévention. The employer therefore must work constantly to maintain or increase their participation in prevention initiatives [31]. Some workers find the document "too theoretical" or "impractical", especially where machinery safety is concerned, often expressing the opinion that the regulation is not adapted to the reality of machinery [32]. Since writing the Programme de prevention is the employer's responsibility, the actual ability of the company directors to produce by themselves an exhaustive list of the risks may be questioned, as may be their ability to propose feasible actions [33].

As in the case of the French document, no model is predefined in the legislation for writing the Programme de prévention, and the resulting document differs from one company to the next. It is not clear what constitutes a compliant document or who is certified to help the employer produce it. The only guide provided by the CNESST is general and rather vague on these questions [26].

The Programme de prévention nevertheless contains a large amount of detailed information, which must be written by the employer and read by employees, who may find the program to be tedious and confusing [2] [11], depending on their education, experience and other factors. Some of the helpful features and inconveniences of the French and Québec versions of the principal document used inenterprises for OHS management are listed in Table 3.

We found the advantageous features and inconveniences to be quite similar for both documents. There are nevertheless opportunities to combine the best features of the Document unique and the Programme de prévention in order to obtain an improved guide for the writing of a complete accident prevention and OHS policy appreciated by employers and employees alike.

\section{Conclusions}

In France and in Quebec, numerous actors play important roles in protecting worker health and safety. In both societies, responsibility for OHS in the 
Table 3. Document unique and Programme de prévention: helpful features and inconveniences.

\begin{tabular}{|c|c|c|}
\hline Support & Document unique & Programme de prévention \\
\hline Helpful features & $\begin{array}{l}\text { - Mandatory for all employers, in } \\
\text { accordance with labor code article } \\
\text { R4121-1. } \\
\text { - The results of the occupational risk } \\
\text { prevention initiative are transcribed } \\
\text { into a single document. } \\
\text { - Is updated annually; is dynamic and } \\
\text { evolves in pace with changes in the } \\
\text { company. } \\
\text { - Makes possible the statistical } \\
\text { monitoring of risk and risk } \\
\text { reduction. } \\
\text { - Promotes decreases in work-related } \\
\text { hazards, and thus less absenteeism, } \\
\text { less expense due to workplace } \\
\text { accidents and work stoppages, } \\
\text { hence a more productive business. } \\
\text { - Is written by the employer with } \\
\text { participation of workers. }\end{array}$ & $\begin{array}{l}\text { The document is complete; its } \\
\text { required content is specified in the } \\
\text { regulation. } \\
\text { - Proposes concrete actions and } \\
\text { measures focused on eliminating } \\
\text { work-related hazards. } \\
\text { - Is updated annually: is dynamic and } \\
\text { evolves in pace with changes } \\
\text { in the company. } \\
\text { - Lists and categorizes the principal } \\
\text { work-related hazards. } \\
\text { - Contains the regulations and } \\
\text { standards applicable to reducing } \\
\text { hazards. } \\
\text { - Promotes decreases in work-related } \\
\text { hazards, and thus less absenteeism, } \\
\text { less expense due to workplace } \\
\text { accidents and work stoppages, hence } \\
\text { a more productive business. } \\
\text { - Is written by the employer with } \\
\text { participation of workers. }\end{array}$ \\
\hline Inconveniences & $\begin{array}{l}\text { - The business owner does most of the } \\
\text { writing; the workload is often } \\
\text { onerous. } \\
\text { - The legislation does not propose a } \\
\text { model; the employer must sort and } \\
\text { weigh the criteria for choosing a } \\
\text { support. } \\
\text { - No exhaustive list of the risks or } \\
\text { categories is proposed in the } \\
\text { legislation; the employer creates his } \\
\text { own referential. } \\
\text { - In many companies, the document is } \\
\text { poorly written, does not reflect } \\
\text { reality, is incomplete and used rarely } \\
\text { if ever. }\end{array}$ & $\begin{array}{l}\text { - Is mandatory only for enterprises in } \\
\text { certain high-priority groups defined } \\
\text { in the legislation. } \\
\text { - There is little research or study on the } \\
\text { effectiveness of this program in small } \\
\text { and medium-sized enterprises. } \\
\text { - Is dependent on occupational health } \\
\text { and safety committees, which are not } \\
\text { always effective. } \\
\text { - Little information is available on how } \\
\text { to write the document. } \\
\text { - Writing of the document is difficult } \\
\text { for employers, who must sort and } \\
\text { weigh the criteria for choosing a } \\
\text { support. } \\
\text { - Employers and workers find the } \\
\text { document too theoretical and of little } \\
\text { practical value. }\end{array}$ \\
\hline
\end{tabular}

workplace lies primarily with the employer. It is up to the employer to evaluate risks, to reduce them and to eliminate them wherever possible, by applying the formal and systematic approaches set forth in the Document unique (France) or the Programme de prévention (Québec).

The frameworks provided by legislation both in France and Québec contain several helpful features as well as notable inconveniences. The present article does not propose solutions, but provides a basis for comparing the Document unique and Programme de prévention in order to create an improved framework that draws upon French and Québécois experience with OHS in small and medium-sized industrial enterprises. In order for in-house OHS management 
based on a single universal document to work as legislators intend and taxpayers expect, the documentation procedure must be made easier and especially more accessible to workers, and the preventive actions must be made both easier to implement and better grounded in workplace reality. The goals must be to improve accident prevention processes and eliminate workplace hazards, and thereby increase business productivity and viability.

\section{Acknowledgements}

The authors thank the Natural Sciences and Engineering Research Council of Canada (NSERC) for financial support through the Discovery Grants Program.

\section{Conflicts of Interest}

The authors declare no conflicts of interest regarding the publication of this paper.

\section{References}

[1] EUROGIP (2010) Prévenir les risques professionnels dans les PME: Quelles actions en Europe? Communiqué de presse, Les Débats du, 14 Octobre 2010, Paris. http://www.eurogip.fr/docs/DP_DebatsEurogip2010_PME.pdf

[2] Tremblay, A. and Badri, A. (2018) Assessment of Occupational Health and Safety Performance Evaluation Tools: State of the Art and Challenges for Small and Medium-Sized Enterprises. Safety Science, 101, 260-267. https://doi.org/10.1016/j.ssci.2017.09.016

[3] Sabourin, G. (2016) L'efficacité des programmes de Mieux-Être au travail, ça se mesure! Prévention au Travail, Reportage.

http://www.preventionautravail.com/reportages/378-1-efficacite-des-programmes-d e-mieux-etre-au-travail-ca-se-mesure.html

[4] Badri, A., Nadeau, S. and Gbodossou, A. (2012) Proposal of a Risk-Factor-Based Analytical Approach for Integrating Occupational Health and Safety into Project Risk Evaluation. Accident Analysis and Prevention: Construction and Engineering, 48, 223-234. https://doi.org/10.1016/j.aap.2011.05.009

[5] Légifrance (2018) Code du Travail. Version Consolidée. https://www.legifrance.gouv.fr/affichCode.do?cidTexte=LEGITEXT000006072050

[6] Institut National de Recherche et de Sécurité (INRS) (2004) Évaluation des risques professionnels. Questions-Réponses sur le Document Unique, 20 p.

[7] Eckerl, G. (2014) Le programme de prévention, un outil méconnu. Prévention au Travail, Reportage. http://www.preventionautravail.com/reportages/134-le-programme-de-preventionun-outil-meconnu.html

[8] LégisQuébec (2018) Loi sur la santé et la sécurité du travail. http://legisquebec.gouv.qc.ca/fr/ShowDoc/cs/S-2.1/

[9] LégisQuébec (2018) Règlement sur le programme de prévention (Loi sur la santé et la sécurité du travail). http://legisquebec.gouv.qc.ca/fr/ShowDoc/cr/S-2.1,\%20r.\%2010/

[10] Kaassis, B. and Badri, A. (2018) Development of a Preliminary Model for Evaluating Occupational Health and Safety Risk Management Maturity in Small and Me- 
dium-Sized Enterprises. Safety, 4, 1-20.

[11] Tremblay, A. and Badri, A. (2018) A Novel Tool for Evaluating Occupational Health and Safety Performance in Small and Medium-Sized Enterprises: The Case of the Quebec Forestry/Pulp and Paper Industry. Safety Science, 101, 282-294. https://doi.org/10.1016/j.ssci.2017.09.017

[12] Tremblay, J.-F. (2018) Définition d'une PME. http://www.dip3.ca/category/pme/

[13] Commission Européenne (2005) Guide de l'utilisateur pour la définition des PME. $60 \mathrm{p}$.

[14] Institut de la statistique Québec (2018) Définition-Petite et moyenne entreprise (PME). Institut de la Statistique Québec.

http://www.stat.gouv.qc.ca/statistiques/science-technologie-innovation/financemen t_pme/cdmi.html

[15] Marchesnay, M. (1991) La PME: Une gestion spécifique. Économierurale, 206, 11-17. https://doi.org/10.3406/ecoru.1991.4231

[16] Mendeloff, J., Nelson, Ch., Ko, K. and Haviland, A. (2006) Small Businesses and Workplace Fatality Risk an Exploratory Analysis. Kauffman-RAND Center for the Study of Small Business and Regulation, $104 \mathrm{p}$.

https://www.rand.org/content/dam/rand/pubs/technical_reports/2006/RAND_TR3 71.pdf https://doi.org/10.7249/TR371

[17] Champoux, D. and Brun, J.-P. (2000) Occupational Health and Safety Management in Small-Size Manufacturing Enterprises. An Overview of the Situation and Orientations for Future Intervention and Research. PISTES, 2-2, $20 \mathrm{p}$.

[18] Ferre, N. (2010) Occupational Health Institutions and Actors in Québec and in France: New Comparative Perspective. PISTES, 12-1, 19 p.

[19] Davezies, Ph. (2008) Le document d'évaluation des risques: Une occasion unique pour débattre sur le travail. Santé \& Travail, 63, 28-30.

[20] Institut National de recherche et de sécurité (INRS) (2018) Principes généraux de la démarche de prévention.

http://www.inrs.fr/demarche/principes-generaux/introduction.html

[21] APS (2018) Document unique d'évaluation des risques professionnels. https://www.aps-prevention.com/document-unique/

[22] Observatoire de la sécurité et de l'accessibilité des établissements d'enseignement (2018) Le programme annuel de prévention. Registres et documents règlementaires, $2 \mathrm{p}$.

[23] SIST VO Santé au travail (2016) Guide d'aide à l'élaboration du document unique. $43 \mathrm{p}$.

[24] Secrétariat du Conseil du trésor (Québec) (2015) Guide d’application de la Loi sur la santé et la sécurité du travail. 36 p.

[25] LégisQuébec (2019) Règlement sur la santé et la sécurité du travail (Loi sur la santé et la sécurité du travail).

http://legisquebec.gouv.qc.ca/fr/showdoc/cr/S-2.1,\%20r.\%2013

[26] Commission des normes, de l'équité, de la santé et de la sécurité du travail (CNESST) (2016) Guide de prévention en milieu de travail à l'intention de la petite et de la moyenne entreprise. 2nd Editon, $40 \mathrm{p}$.

[27] Direction de la santé des personnes au travail (2013) Santé et sécurité du travail: Guide pour élaborer un programme de prévention. $40 \mathrm{p}$. 
[28] Perrot, M. (2018) L'essentiel à connaître sur le Document unique d'évaluation des risques professionnels.

https://www.blog-expertises-publiques.com/lessentiel-a-connaitre-sur-le-document -unique-devaluation-des-risques-professionnels

[29] Affaires, R.H. (2018) LaBonté, D. Les principaux avantages des programmes de prévention.

http://www.affairesrh.ca/gestionnaires/coin-gestionnaire/fiche.aspx? $\mathrm{p}=459895$

[30] Baril-Gingras, G., Vézina, M. and Lippel, K. (2013) Bilan relatif aux dispositions de la LSST: Vers une application intégrale? Industrial Relations, 68, 682-708.

[31] Allaire, E., Jauvin, N. and Duchesne, A. (2016) Démarche participative de prévention des problèmes de santé et sécurité au travail chez les auxiliaires de santé et de services sociaux du Centre intégré universitaire de santé et de services sociaux (CIUSSS) de la Capitale-Nationale. Centre de santé et de services sociaux (CSSS) de la Vieille-Capitale, $20 \mathrm{p}$.

[32] Champoux, D. and Brun, J.-P. (2010) Provisions, Capacities and OHS Practices in Small Businesses: Opinions of Employers, Employees and OHS Practitioners in Québec. PISTES, 12-2, $22 \mathrm{p}$.

[33] Imbeau, D., Aubry, K. and Chiasson, M.-E. (2012) Suivi du déploiement d'un programme d'amélioration continue augmenté d'un volet SST/ergonomie dans une entreprise manufacturière au Québec: Recherche-action 2003-2010 (Rapport technique n EPM-RT-2012-04). 